\title{
CONVERSANDO SOBRE TEXTOS NA ALFABETIZAÇÃO: O PAPEL DA MEDIAÇÃO DOCENTE*
}

\author{
Ana Carolina Perrusi Brandão* \\ Telma Ferraz LeaL ${ }^{* *+}$ \\ Bárbhara Elyzabeth Souza Nascimento ${ }^{* * *}$
}

\begin{abstract}
RESUMO: Com base na teoria sociointeracionista e na abordagem da alfabetização na perspectiva do letramento, o artigo analisa situações de conversa sobre textos escritos em duas salas do $1^{\circ}$ ano do primeiro ciclo do ensino fundamental. As situações foram extraídas de uma sequência didática planejada para o ensino do gênero reportagem. Os momentos de leitura e conversa sobre as reportagens conduzidos por cada professora foram audiogravados e, posteriormente, transcritos. Para a análise desses dados foram identificados os tipos de perguntas formulados pelas professoras (antes, durante e depois da leitura) e as habilidades de compreensão estimuladas nas crianças. A análise evidencia o papel fundamental da mediação docente para o desenvolvimento da compreensão de textos escritos em crianças em processo de alfabetização.
\end{abstract}

Palavras-chave: Ensino da compreensão. Conversa sobre textos. Leitura. Alfabetização.

Apoio: CNPq e Facepe.

** PhD em Psicologia e professora adjunta do Centro de Educação da Universidade Federal de Pernambuco (UFPE).E-mail: <carolperrusi@ufpe.br>

*** Doutora em Psicologia e professora do Departamento de Métodos e Técnicas de Ensino e da Pós-Graduação em Educação da Universidade Federal de Pernambuco (UFPE).

E-mail:<tfleal@terra.com.br>

**** Mestre em Educação, pedagoga e coordenadora de formação geral no Instituto Federal Pernambuco (IFPE). E-mail: <barbhara@pesqueira.ifpe.edu.br>

Disponível em <http://www.cedes.unicamp.br> 


\title{
TALKING ABOUT TEXTS IN IST GRADE CLASSES: THE ROLE OF TEACHER MEDIATION
}

\begin{abstract}
Based on the social interactionist theory and the approach to reading instruction from the perspective of literacy, this article analyzes children talking about written texts in two first grade classes. The situations were extracted from a didactic sequence planned for teaching the news report genre. Text reading and discussion activities conducted by each teacher were audio taped and later transcribed. For the analysis of the data, the types of questions formulated by the teachers (before, during and after the reading activity) and the comprehension skills stimulated in the children were identified. The analysis clearly shows the essential role played by the teacher in the development of written text comprehension during the process of learning to read.
\end{abstract}

Key words: Teaching comprehension. Talking about texts. Reading. Reading instruction.

\section{Introdução}

E

nsinar a ler é, incontestavelmente, uma das tarefas da escola. Pesquisadores de diferentes linhas teóricas, equipes técnicas de secretarias de Educação, coordenadores pedagógicos, professores, pais, alunos... Todos concordam que a escola deve ensinar a ler. No entanto, alguns conflitos começam a surgir quando se pergunta sobre o que é ensinar a ler ou como se ensina a ler.

Tradicionalmente, o ensino da leitura seguia uma sequência fixa: primeiro se ensinavam as letras, depois as sílabas, palavras e textos cartilhados (próprios para o treino dos padrōes silábicos). Somente no suposto final do percurso se investia na leitura de textos que circulam fora da escola, seguida de perguntas feitas pela professora. Vale observar que nesse modelo de ensino parece ficar implícito que a compreensão dos alunos só passaria a ser foco de atenção no momento em que pudessem ler com certa autonomia. Além disso, ao que parece, essa "atenção" estaria mais voltada para a "avaliação da compreensão" do que para o "ensino de habilidades para entender o texto", tópico que, mais recentemente, tem sido discutido por pesquisadores brasileiros (ver, por exemplo, MENIN et al., 2010).

Diferentemente das antigas cartilhas, em alguns dos atuais livros para alfabetizar estão presentes textos encontrados em diferentes esferas sociais 
como a literária, a publicitária, a jornalística, a doméstica. São textos produzidos para atender a diferentes propósitos, com unidade de sentido e que são levados para os livros didáticos com intenção de aproximar as crianças dessas esferas de interação, assumindo-se a concepção de que ler é uma atividade de produção e apropriação de sentido, tal como defendem Marcuschi (2008) e Koch e Elias (2010).

Embora presente na maior parte dos livros didáticos aprovados no Programa Nacional do Livro Didático para o Ensino Fundamental, tal pressuposto, porém, nem sempre é adotado em materiais dirigidos à alfabetização, tais como o livro Aprender a ler, de Oliveira e Castro (2008). Vejamos alguns textos desta obra, propostos para serem lidos pelas crianças:

A aula

Leila ia à aula.

- A aula é ali?

- A aula é ali, Leila?

Leila leu: "A leoa e a lua." (p. 41)

Milu é uma mula.

A lama é mole. Ela mela.

Eu leio. Aleluia!

Mimi miou: miau, miau! (p. 48)

Consideramos que textos dessa natureza contribuem para "ensinar" as crianças que a leitura está associada a um ato simplesmente mecânico, em que não há nada para ser compreendido. Fazem, portanto, um enorme desserviço que pode custar caro para a constituição das crianças como leitoras.

A esse respeito, Charmeux (1994) aponta que a falta de consciência de que os textos são objetos de comunicação e que, dessa forma, demandam um esforço de construção de sentidos seria, justamente, uma primeira dificuldade para a aprendizagem da leitura. Além disso, a autora salienta que textos como os apresentados anteriormente podem, no mínimo, fazer com que as crianças pensem que 
[...] a compreensão chegue sozinha, como num passe de mágica [...] fazer desaparecer essa atitude passiva de espera de sentido é o primeiro remédio às dificuldades de leitura. Fica claro, a partir daí, que sem dúvida é mais inteligente evitar sua aparição no momento das primeiras aprendizagens. (CHARMEUX, op. cit., p. 88)

Nessa perspectiva, Charmeux (ibid.) ressalta ainda que

Ensinar a leitura, portanto, é colocar em funcionamento um comportamento ativo, vigilante, de construção inteligente de significação, motivado por um projeto consciente e deliberado, e isto desde o próprio início da escolaridade das crianças, e mesmo antes que elas cheguem à escola.

Em síntese, "compreender exige habilidade, interação e trabalho" (MARCUSCHI, 2008, p. 230). Com base nos argumentos já expostos, é evidente que o contato com textos de boa qualidade deve ocupar um lugar de destaque nas salas de alfabetização. É também por meio do contato com textos inseridos em práticas de leitura que tenham significado para as crianças, tais como a leitura de histórias ou a leitura de um folheto de prevenção contra o dengue, que elas desenvolvem os chamados "gestos de leitura” (CHARTIER; CLESSE; HÉRBRARD, 1996) adequados a diferentes suportes e finalidades dessa atividade. Tais aprendizagens vão fazer com que a criança aborde diferentemente a tarefa de ler uma história e a de ler um convite, por exemplo.

Apresentar ingressos para uma peça de teatro ou um filme, instruções de jogos, convites de aniversário ou cartazes educativos e estimular as crianças para que descubram, por meio de uma "pesquisa de indícios", as finalidades desses textos e construam o significado da mensagem escrita deve ser, portanto, uma prática constante em salas de alfabetização, tal como propõem Chartier et al. (1996).

No entanto, como temos argumentado (BRANDÃO, 2006; BRANDÃO; ROSA, 2010), além de propiciar situações em que as crianças busquem sentidos gerais do texto, também é essencial que a professora leia textos em voz alta para elas e que converse sobre esses textos de modo a engajar os ouvintes numa proposta conjunta de compreensão. De fato, como alertam Girotto e Souza (2010, p. 53), mesmo para as crianças que já leem com certa fluência nessa etapa inicial, a compreensão "não se dá necessariamente durante o ato de ler da criança solitária e silenciosamente", sendo, portanto, fundamental sua interação com o professor e demais colegas. 
Construindo sentido sobre o texto com o outro: a mediação docente no momento da leitura

Ensinar leitura nos dois primeiros anos do ensino fundamental é uma tarefa complexa, que ocorre em um momento em que os professores precisam também fazer com que as crianças compreendam o sistema alfabético de escrita. Nas propostas curriculares atuais, como vem sendo discutido por Leal e Brandão (2012), há uma demanda de que os docentes não só ensinem o sistema de escrita, como também introduzam, desde cedo, as situações de compreensão e produção de textos. Contemplar ambas as dimensões do ensino não é tarefa fácil para os professores.

Em uma pesquisa sobre práticas docentes, Carvalho (2012) analisou aulas de duas professoras consideradas boas alfabetizadoras e que afirmavam trabalhar com textos desde o início da alfabetização. Ela evidenciou que as professoras, embora dedicassem tempo pedagógico para o ensino da leitura e produção de textos, "aproveitavam" tais atividades para ensinar o sistema de escrita alfabética, minimizando muitas vezes as reflexōes sobre o texto a ser lido/produzido, para explorar características das palavras. Desse modo, algumas escolhas dos textos eram motivadas pela possibilidade de abordar o ensino do sistema de escrita.

Essa tendência representou certamente uma busca das docentes por "alfabetizar com textos", respeitando o princípio de que textos autênticos são os legítimos recursos a serem adotados na escola e não textos sem sentido, que dissociam leitura e compreensão, como os que comentamos anteriormente. Tal proposta, no entanto, revelou também certa dificuldade de compreensão das docentes acerca dos objetivos relacionados ao trabalho realmente focado nos eixos de produção e compreensão de textos.

Concebemos que o ensino desses eixos requer que se defina claramente que conhecimentos/capacidades precisam ser ensinados e os modos como devem ser abordados. Defendemos que tópicos relativos à reflexão sobre aspectos sociodiscursivos dos textos precisam ser contemplados, tais como a identificação da finalidade do texto, o contexto em que foi criado, os destinatários pretendidos. Além disso, é fundamental desenvolver estratégias de leitura, como as habilidades de antecipar sentidos do texto, elaborar inferências, localizar informaçôes, estabelecer relaçóes entre textos, entre outras.

Com base em Solé (1998), temos argumentado que uma das possibilidades para materializar esse tipo de ensino é a conversa sobre os textos 
que são lidos para as crianças. Assim como Colomer e Camps (2002, p. 85), entendemos, portanto, que

[...] a discussão baseada no texto ajuda os estudantes a enriquecerem sua compreensão ao oferecer-lhes as interpretações dos demais, reforça sua memória a longo prazo, já que devem recordar a informação para explicar o que entenderam, e contribui também para melhorar a compreensão em profundidade e o pensamento crítico quando os alunos têm de apresentar argumentos sobre opinióes emitidas e têm de eliminar as incoerências e contradiçôes lógicas de seu próprio pensamento com relação ao texto lido.

Nessa direção, também compartilhamos com Riter (2009) a importância de planejar a conversa sobre os textos. Entendemos que a forma de condução desse diálogo é fundamental para engajar (ou não) os alunos na construção de sentido, estimulando o uso de estratégias de interação com os textos que poderão ser incorporadas e utilizadas por eles em suas próximas leituras, sem a presença de mediadores (BRANDÃO; ROSA, 2010).

A esse respeito, Lerner (2002) salienta que os comportamentos leitores apresentam duas dimensões: uma pública/interpessoal e outra privada/ psicológica. Na primeira, estão os comportamentos do leitor implicados na interação com outras pessoas acerca dos textos; por exemplo, comentar ou recomendar algo que lemos ou discutir uma interpretação de um livro que foi lido. A dimensão privada, por sua vez, refere-se, segundo Lerner (op. cit.), à relação pessoal do leitor com os textos, por exemplo: ao selecionar a forma como irá ler determinado texto em função do seu objetivo, ao reler um trecho não compreensível, ao saltar o que não foi compreendido ou o que considerou pouco importante. A autora destaca ainda que ensinar os comportamentos do leitor (e do escritor) quando estes estão envolvidos em práticas sociais de leitura e escrita é, sem dúvida, um conteúdo escolar essencial.

Nesse sentido, vale frisar que "a forma de pensar dos alunos sobre o texto é muito determinada pela maneira como os professores lhes pedem que pensem por meio de suas perguntas e propostas" (CAMPS; COLOMER, 2002, p. 85).

Considerando, então, o planejamento da conversa sobre os textos em qualquer nível de ensino, é preciso refletir sobre algumas questões: o que iremos ler?; sobre o que conversaremos antes da leitura?; como conduziremos a 
leitura propriamente dita?; que perguntas darão início à conversa após a leitura do texto e, se for o caso, que atividades de extensão da leitura poderão ser propostas? Além disso, é preciso estar disponível para ouvir o que as crianças têm a dizer, percebendo, ao longo da leitura, como vão compreendendo o texto e que conexões fazem entre este e suas vivências ou com outros textos já conhecidos.

Com base nas considerações feitas anteriormente, no presente artigo iremos refletir sobre a mediação docente em situações de conversa sobre reportagens lidas para crianças em salas de alfabetização.

\section{Situando a pesquisa}

De natureza qualitativa, os dados aqui analisados foram coletados em uma pesquisa que envolveu um grupo coordenado pelas duas primeiras autoras do artigo. Participavam do grupo alunos da graduação (como era o caso da terceira autora do artigo na época), da pós-graduação, bem como professoras do $1^{\circ}$ e $2^{\circ}$ ciclos do ensino fundamental de escolas municipais do Recife. A nossa proposta era planejar conjuntamente sequências didáticas, com base em reflexôes realizadas pelos autores Schneuwly e Dolz (2004). O planejamento era implementado pelas professoras participantes junto ao seu grupo de alunos. Os encontros para estudo e planejamento dos módulos das sequências ocorriam na universidade, no contraturno das professoras.

As sequências didáticas desenvolvidas eram observadas por duplas de alunos que também participavam do grupo, sendo realizadas em datas previamente combinadas com as professoras. As aulas eram gravadas, sendo algumas também filmadas. Após a etapa de observação da sequência, era realizada a transcrição literal dos dados com a produção de relatórios de aula para posterior análise das práticas encaminhadas.

Neste artigo, analisamos dados extraídos da sequência conduzida por duas professoras do $1^{\circ}$ ano do $1^{\circ}$ ciclo da Rede Municipal de Ensino do Recife, voltada para o trabalho com o gênero reportagem. A professora 1 tinha um grupo com 22 crianças na faixa etária de 6/7 anos. A professora 2 , por sua vez, tinha um grupo com 18 crianças na mesma faixa de idade.

Nas duas salas, a leitura das reportagens foi feita sempre pela professora e as conversas transcorreram sempre no grande grupo. Em alguns momentos, as crianças foram chamadas a descobrir do que se tratava a 
reportagem a ser lida, se aventurando na leitura de algumas palavras, do título da reportagem ou de legendas de fotos apresentadas no texto.

Finalmente, a professora 1 concluiu a sequência planejada em 11 aulas e a professora 2, em oito aulas. Observou-se ainda que a professora 1 desenvolveu um maior número de atividades de discussão das reportagens lidas (dez aulas) em relação à professora 2 (cinco aulas). Por outro lado, como veremos a seguir, a professora 2 investiu mais na reflexão sobre os textos lidos.

\section{A leitura e a conversa sobre reportagens na sala da professora 1}

A professora 1 promoveu momentos de leitura em voz alta de várias reportagens, englobando temas diversos. Em cinco das dez aulas em que a professora leu reportagens foram registradas perguntas de previsão sobre o texto, estimulando as crianças a antecipar sentidos e a levantar hipóteses com base em seus conhecimentos prévios e nas pistas textuais. Tal procedimento, claramente, motivava o grupo a escutar a leitura atentamente. Vejamos um exemplo:

Fragmento 1 - Reportagem: "Sem leitos para vítimas de dengue"

P: - Essa reportagem que saiu aqui, no Jornal de Domingo, que é essa daqui, oh. (A professora mostra a reportagem para as crianças). É essa reportagem aqui, onde tem essa fotografia, tão vendo? Eu vou mostrar aí de perto, certo? (A foto apresentava o mosquito transmissor da dengue).

A: - Cadê, tia?

P: - É essa daqui!

A (olhando para a imagem da reportagem): - É sobre o mosquito da dengue! P: - É, eu vou ler aqui para vocês. Essa reportagem, eu já ouvi algumas pessoas dizerem sobre o que é, mas eu vou perguntar de novo! É sobre o quê?

(Vários alunos falam ao mesmo tempo sobre o que acham que está escrito na reportagem e a professora organiza a vez de quem vai falar)

A: - A roupa do mosquito da dengue...

A: - A mulher que mata a dengue...

A (vários): - É sobre o mosquito da dengue!

P: - Mosquito da dengue, por que vocês acham que é sobre o mosquito 
da dengue? Eu nem li ainda pra vocês, por que vocês acham que é sobre o mosquito da dengue, isso aqui?

\section{A: - Porque eu vi na televisão!}

No trecho descrito vemos que a professora consegue instigar as crianças a se engajar na construção de sentido do texto a ser lido. Assim, pode-se inferir que, para ela, a leitura era concebida "como uma atividade social e interativa, voltada à construção de sentidos, que são gerados na interlocução leitor-texto-autor através do intercruzamento das várias informações no texto e entre elas e os conhecimentos prévios do leitor" (FERREIRA; DIAS, 2005, p. 11).

Nessa perspectiva, a docente estimulou a geração de expectativas sobre a temática a ser tratada na reportagem, bem como chamou a atenção sobre a foto, um elemento importante para dar pistas sobre o tema do texto. As crianças, por sua vez, responderam e se mostraram interessadas.

Durante a leitura das reportagens, também pudemos observar que as intervenções da professora tendiam a ocorrer apenas quando as crianças interrompiam a leitura para fazer algum comentário ou levantar dúvidas, como ilustra o fragmento a seguir:

Fragmento 2 - Reportagem: "Sem leitos para vítimas de dengue"

P: (inicia a leitura): - O título, o nome da reportagem, é: "Sem leitos para vítimas de Dengue", né? Isso é um assunto muito importante, minha gente, porque a dengue não é uma doençazinha qualquer, não é uma doença que a gente deve deixar para lá, não. É uma doença que a gente tem que cuidar muito, não é uma doença que é uma besteira. Eu vou ler a reportagem todinha, tá certo?

(Inicia a leitura e na sequência uma das crianças faz um comentário)

A: - Por isso que eu matei dois mosquitos ontem!

P: (retoma a leitura) - "Na Segunda- Feira, Vanderson Gomes Pereira, oito anos, morador do bairro de Cavaleiro, em Jaboatão, morreu no Hospital da Restauração, na capital, vítima de dengue hemorrágica [...]”.

A: - De dengue, tia?!

P: - É! (A professora continua a leitura da reportagem): "Inicialmente ele foi atendido no hospital Otávio de Freitas e teve o diagnóstico errado, os médicos achavam que o garoto tinha apendicite $[\ldots]$ ". 


$$
\begin{aligned}
& \text { A: - Morreu foi? } \\
& \text { P: - Foi! }
\end{aligned}
$$

Vemos nesse fragmento que, embora a professora estivesse atenta aos comentários das crianças, ela própria não tomava a iniciativa de formular perguntas e ajudá-las na construção de sentidos.

Tal como é discutido por Solé (1998), lançar questões de previsão ou inferenciais durante a leitura pode, muita vezes, oportunizar uma melhor compreensão de elementos que poderiam passar despercebidos e provocar, mais adiante, problemas de compreensão do texto.

Um dado interessante na sala da professora 1 é a evidência de que o grupo, de fato, está muito engajado na tarefa de construir sentido durante a leitura. Ou seja, para as crianças, a leitura precisa ter significado e isso denota o trabalho anterior da professora nessa direção. Vejamos um claro exemplo disso no fragmento a seguir com a leitura da reportagem "Bicho homem", que descreve a experiência de um casal de biólogos e três crianças que ficaram numa jaula na área dos primatas, no Zoológico de Sorocaba (SP), com o intuito de levar os visitantes a refletir sobre os animais que estão no zoológico e o comportamento pouco respeitoso que, por vezes, adotamos diante deles.

Fragmento 3 - Reportagem: "Bicho homem"

P: - (lendo a reportagem) "Segundo ele, o objetivo da experiência era educar o público. 'Queríamos ver se vendo o bicho homem, enjaulado, o visitante também vai jogar nele pedras, paus e alimentos como faz com os outros animais' [...]".

(Um aluno interrompe a professora)

A: - Tia, é parte homem e parte cavalo, é?!

P: - Não! Isso aqui foram pessoas mesmo que ficaram na jaula! $\mathrm{Na}$ jaula do zoológico.

A: - Mas era um bicho mesmo que virou homem?!!

P: - Não! São pessoas normais! Foram funcionários do zoológico que aceitaram ficar o dia todo enjaulados, como se fossem animais, para que as pessoas que fossem visitar o zoológico vissem as pessoas ali, enjauladas, para ver como elas ficavam, o que elas faziam! Tá? Eu vou ler, para vocês verem o que aconteceu. 
P: - Olha aqui o que o diretor do zoológico diz (relê o trecho que havia lido): "Queríamos ver se, vendo o bicho homem, enjaulado, o visitante também vai jogar nele pedras, paus e alimentos como faz com os outros animais', afirmou [...]".

Provavelmente, se não fossem "ouvintes-ativos", os alunos seguiriam ouvindo a reportagem sem buscar compreender o que significaria ser um "bicho homem" e a justificativa de utilizar essa expressão na reportagem. Vale reforçar, porém, que são as crianças que questionam a professora durante a leitura.

Nos momentos após a leitura da reportagem, observamos que a professora 1 tendia a fazer mais questôes de natureza literal. Por exemplo, após a leitura da reportagem "Filhos do coração", foram feitas as seguintes perguntas: "quem foram as pessoas entrevistadas?"; "O que disse Juninho (um dos entrevistados)?”.

Assim, de modo geral, as questôes de compreensão eram pouco diversificadas e a professora não investia muito na expressão de opiniōes sobre o tema da reportagem ou sobre os pontos de vista presentes no texto. Apenas em uma das aulas, vimos que a docente chegou a solicitar a opinião das crianças sobre o ponto de vista do autor de uma reportagem intitulada "Cuidado com a pipa!": - Esse autor aqui, ele acha que é perigoso ou não soltar papagaio, colocar cerol na pipa?. Porém, não potencializou esse momento, perdendo a oportunidade de aprofundar as respostas das crianças e contribuir para uma maior reflexão sobre o texto.

Observamos, em alguns momentos, certa ansiedade da professora em relação ao ensino do gênero, buscando enfatizar na discussão com as crianças aspectos composicionais ou sociodiscursivos relativos a reportagens. Entendemos, porém, que é importante mesclar esse tipo de intervenção com questôes que levem as crianças a compreender o que diz o autor do texto e a expressar seus pensamentos sobre o tema. Afinal, quando lemos uma reportagem, buscamos, comumente, nos informar sobre determinado tema que nos interessa e nos posicionar criticamente diante dele, conhecendo diferentes opiniōes sobre o tópico.

Nessa perspectiva, é importante que a conversa após a leitura possa ganhar esse rumo, tal como aponta o fragmento a seguir, após a leitura da reportagem "Bicho homem", já citada aqui:

Fragmento 4 - Reportagem: "Bicho homem" 
P: - Vejam, nesse zoológico aqui, eles normalmente estavam com esse problema, das pessoas maltratarem, jogarem coisa na jaula, aí fizeram essa experiência, o que vocês acharam dessa experiência do zoológico?

A: - Eu não achei nada certo!

P: - Não achou certo?! Por quê?

A: - Porque eu não achei nada certo, não!

P: - Por que não achou nada certo? Diga!

A: - Porque, porque não pode maltratar os bichos!

P: - Não, eu tô falando aqui, não pode maltratar os bichos, mas essa experiência que eles fizeram, de colocar pessoas humanas dentro da jaula?

A: - Eu não achei que é certo, não, quem fica dentro da jaula é ladrão!

P: - Foi o que disse o menino Tiago, mas a menina aqui (referindo-se aos entrevistados na reportagem) teve outra opiniáo, que seria bom porque aprendia a não maltratar os animais, o que vocês acharam, quem poderia dar a sua opinião?

A: - Não pode deixar gente dentro da jaula, não!' A pessoa pode se machucar com os animais, eles mordem...

P: - Mas na jaula só tinha ser humano, não era junto com animais, não!

A: - Tia, porque os animais podem morder...

P: - Cada animal fica na sua jaula, os animais não ficam todos juntos, não! Tem o zoológico que é dividido por ala, tem a ala que ficam os primatas, que são os macacos, aí é assim, cada animal fica na sua ala, então, os homens ficaram na jaula, não tinha animal dentro, não, só as pessoas!

A: - Tinha macaco, era o animal que tava do outro lado!

A: - Os humanos ficaram imitando bicho, foi?!

P: - Não! Tanto é que aqui diz (a professora retoma ao que está escrito na reportagem e lê): “a jaula tinha móveis, equipamentos, televisão, geladeira"... certo? Tudo o que eles queriam...

A: - Tinha cama?!

P: - É, tinha móveis, significa, cama, cadeira para sentar, mesa, tinha tudo! Só que era uma jaula, do zoológico!

A: - Mas numa jaula não cabe tudo isso, não!

P: - Mas a jaula era grande, eles construíram uma jaula de $50 \mathrm{~m}^{2}$ ! 
$\mathrm{Na}$ discussão conduzida pela professora vemos que ela tentava levar as crianças a dialogar com o texto e a se posicionar diante do que estava dito. No entanto, elas ainda tinham muitas dúvidas a respeito do que dizia a reportagem. Pareciam não estar compreendendo claramente por que tal "experiência" tinha sido feita e isso acabou por comprometer a qualidade desse diálogo.

No trecho seguinte, a professora perguntou se as crianças "acharam certo", "se concordaram" ou "se gostaram" "da experiência”. Porém, como se pode ver a seguir, sem compreender o sentido do que ocorreu, as crianças pareciam se fixar em seus conhecimentos prévios de que "não se pode maltratar os animais". Vejamos:

Fragmento 5 - Reportagem: "Bicho homem"

P: - Quem concordou com a experiência e quem não concordou? [...]

P: - Você disse que não concordou! Por quê? (O aluno não responde)

P: - Por que você não gostou da experiência?

A: - Porque...

P: - Por que você não gostou da experiência de humanos ficarem dentro da jaula?! O que você acha disso?!

A: - Eu ia desmaiar!

P: - Tu teria desmaiado, é?!

A: - Não é certo maltratar os bichos, dar comida envenenada...

P: - Não! Ninguém acha certo, não, mas tem muitas pessoas que fazem isso, né?!

A análise das falas das crianças nos fragmentos apresentados reforça a necessidade de discutir mais sobre o tema antes de começar a ler textos dessa natureza para elas. No caso dessa reportagem, por exemplo, a professora, ao anunciar a leitura, pediu apenas que o grupo prestasse atenção, pois pretendia discutir o texto ao final da leitura. Assim, o tema ou o título da matéria não foram explorados antes da leitura e, durante ela, as crianças não receberam ajuda para elaborar a compreensão do texto. A discussão ocorreu apenas ao final da leitura e tal procedimento não contribuiu para uma compreensão mais aprofundada do texto pelas crianças. 


\section{A leitura e conversa sobre reportagens na sala da professora 2}

A professora 2 também valorizava a leitura de reportagens e o trabalho de conversa sobre o texto. No caso dessa sala, as crianças se interessavam por ler certas palavras num clima bastante animado de descoberta.

Diferentemente da professora 1, observamos que essa docente interrompia a leitura algumas vezes para discutir trechos do texto. Nesses momentos, ela retomava elementos do texto que considerava importantes para a compreensão das crianças.

A professora 2 também preocupava-se mais em explorar o momento anterior à leitura, conversando sobre o tema da reportagem que pretendia ler. Vejamos, por exemplo, como ela conduziu o diálogo com as crianças quando leu a reportagem "Cuidado com a pipa!":

Fragmento 1 - Reportagem: "Cuidado com a pipa!"

P: (relembrando a conversa iniciada no dia anterior em que anunciou que fariam um jornal mural para colocar as reportagens produzidas na sala) [...] E a gente começou falando sobre pipa, não foi?

A: - Foi!

P: - Uma brincadeira que vocês gostam! Aí todo mundo falou que gostava de pipa! Aí o que é que a gente iria fazer?

(aluna interrompe a fala da professora)

A: - Mas tem que ter cuidado!

P: - Tem que ter cuidado por quê, Carol?

A: - Por causa do cerol!

(Os alunos falam ao mesmo tempo)

A: - Do cerol!

P: - De um por um, todo mundo pode falar, agora, esperando a vez do outro, tá? Fale, Camila!

A: - Por causa do cerol que... ai tá preso... uns negócios pra fazer... aí corta a pessoa.

P: - Corta a pessoa. Brincadeira de pipa é boa, mas é perigosa, não é? Aí Juliana disse que é perigosa por quê, Juliana? O que é que o cerol faz?

A: - Eh, corta a pessoa! 
P: - Quem mais? Carol, diga!

A: - O cerol, né? Que ele corta muito e já cortou meu amigo uma vez quando ele tava passando.

P: - Cortou onde? Qual foi o lugar que cortou nele? O dedo?

(A aluna balança a cabeça afirmando)

P: - Foi, ele tava passando cerol na pipa, foi? Quem mais gostaria de falar? $[\ldots]$

A: - Mas meu irmão pegou uma vez no cerol, mas não se cortou, não!

P: - Se cortou, não?

(Aluno faz sinal de negativo com a cabeça)

P: - Por que será que ele não se cortou?

A: - Porque botou assim na mão aqui, aí passou assim na linha (mostrando como seu irmão pegou no cerol)

P: - E vocês concordam que isso é uma brincadeira legal? Gostam de usar o cerol?

A: - Eu não!

A: - Eu não confio, não!

A reportagem tratava do uso do cerol nas brincadeiras com pipa e dos acidentes que isso poderia causar. Apesar do título "Cuidado com a pipa", o texto também destacava que se tratava de uma brincadeira inofensiva quando realizada adequadamente. A conversa sobre o tema do texto antes da leitura e as várias questōes levantadas acerca dessa brincadeira foram, portanto, um bom mote para convidar as crianças a escutar a reportagem e se engajar nesse trabalho mental que é compreender um texto. Além disso, esse tipo de procedimento ativa conhecimentos prévios relevantes sobre o tema que podem contribuir para a compreensão.

Como já foi dito, a docente também dava algumas pausas durante leitura, ajudando as crianças a compreender o texto. Vejamos um fragmento que claramente confirma essa afirmação:

Fragmento 2 - Reportagem: "Bicho homem"

P: - Sentadinhos que eu vou contar!

P: - Tchan, tchan, tchan, tchan (faz suspense para iniciar a leitura da reportagem). 
"Sete horas, dois adultos, três crianças permaneceram fechadas em uma das jaulas, expostas ao grupo. A jaula foi a mais visitada no dia do zoológico".

(risos das crianças)

P: - Quem é que ficou preso, gente?

A: - Eh, um casal e três crianças!

P: - Um casal e três crianças? Como que você sabe que é casal?!

A: - Porque é uma mãe e um... uma mulher e um homem.

P: - Quem foi que disse que é uma mulher e um homem?

A: - Porque tem três filhinhas!

P: - Aqui diz que "dois adultos", não diz que é um casal, mas Juliana adivinhou! É uma detetive muito boa essa menina!

(As crianças começam a cantar para Juliana)

P: - Muito bem, Ju! [...].

P: (continua a leitura) - "Entre as dez horas e dezessete horas um casal de biólogos que trabalham no local e três crianças de idade entre 4 e 12 anos, filhos de um funcionário, ficaram no local por cerca de cinquenta metros quadrado equivalente a um apartamento de um quarto [...]".

(Uma criança pede para olhar a reportagem mais de perto).

P: - Depois eu mostro.

P: - (continua a leitura) "O recinto fica na ala dos primatas e a jaula recebeu nove equipamentos modernos como TV, geladeira, aparelho de som, computador e telefone celular”. Até aqui vocês entenderam essa reportagem?

A: - Entendeu!

P: - Carol, essa reportagem tá falando de quê?

A: - Tá falando, né... sobre né... que o casal também que por um minuto ficaram lá (na jaula).

A: - Aí botou coisas pra eles ficarem lá, né? Como se fosse uma casa deles. Botou televisão, equipamento de rádio, botou sofá, cama, geladeira, muita coisa! $\mathrm{P}:-$ coisas que...

A: - E telefone! 
P: - Coisas que tão dentro de onde?

A: - Da casa!

A: - Cadeira, mesa, comida, tudo!

A: - Não! Comida eles sai da jaula pra pegar!

P: - Mas, veja bem! Olha só o que ele tá dizendo! (continua lendo): "reproduzimos os ambientes de uma casa para que o visitante pudesse observar o homem em seu habitat natural, explicou o veterinário Rodrigo Hidalgo Teixeira, diretor do zoológico. Segundo ele, o objetivo principal da experiência era educar o público. - Queríamos ver se, vendo o bicho homem, enjaulado, o visitante também vai jogar nele pedras, paus e alimentos como faz com os outros animais".

A: - É porque pra não bater pedras na cabeça dele e acontecer alguma coisa com eles!

P: - O que é que o diretor do zoológico tava querendo com essa experiência?

A: - Tava querendo, tia... porque, tia, o diretor num quer que ele jogue na jaula.

A: - Jaula!

A: - Na jaula, né? Porque ele num quer que haja acidente!

P: - Não jogar o quê?

A: - (coro) Pedras!

A: - E também pra não machucar! [...].

Vemos que, durante a leitura da reportagem, a professora 2 lançou perguntas para as crianças, tentando retomar o que leu e estimular que identificassem o ponto de vista do diretor do zoológico. A docente também se mostrou atenta aos comentários das crianças, valorizando as inferências que realizaram, como no trecho em que Juliana deduziu que os dois adultos que estavam indo para a jaula eram, provavelmente, um casal com seus filhos.

Finalmente, a professora 2 conversou com as crianças ao final $\mathrm{da}$ leitura das reportagens, como vemos no fragmento a seguir:

Fragmento 3 - Reportagem: "Cuidado com a pipa!"

P: - Aí a gente teve aí uma reportagem. Essa reportagem ta falando o quê? 
A: - De cerol.

A: - De pipa.

P: - Sim, mas o que foi que ela contou sobre isso?

(Os alunos levantam-se e ficam falando todos ao mesmo tempo)

P: - De um em um!

A: - Ela contou que... uma menina que teve um sonho de celebridade aí tava na janela vendo o rio e ai veio a pipa e cortou ela.

P: - Mas ela estava... ela teve um sonho de celebridade?!!

A: - Não! (todos).

P: - Ela teve um sonho...

A: - De reportagem!

P: - A menina teve um sonho.

A: - De reportagem.

P: - Reportagem? Oh, o sonho dela era ver o...

A: - (coro) Rio!

P: - Mar! E ela estava indo, não foi?

A: - Foi!

P: - Ela estava indo e como se encontraram naquele momento que aconteceu o acidente? Onde é que ela tava?

A1:- Na janela.

$\mathrm{P}-\mathrm{Na}$ janela? Quem lembra?

A2: - E a mãe dela botou a toalha num foi, tia?

P: - Botou a toalha para estancar o sangue!

A3: - Mas quando chegou no hospital, morreu! [...].

P: - Mas era ela que tava empinando pipa?

A2: - Não! Era um menino!

P: - Era alguém, não ta dizendo aqui quem foi, né? Ela ia passando em cima de uma...

A3: - Pipa.

A4: - Não! 
P: - "De pé na caçamba de uma picape" (professora relê o trecho da reportagem).

P: - Quem sabe o que é caçamba?

A5: - Eu sei, tia! É muito funda e tem muita água!

P: - Caçamba, não! Isso é cacimba!

(Todos falam ao mesmo tempo)

Observamos que a professora tanto formulava questóes literais, em que ela buscava relembrar o que dizia a reportagem, como é o caso do fragmento anterior, como também estimulava a discussão sobre a temática ("Você, se fosse empinar pipa, você iria concordar que alguém colocasse cerol na linha da sua pipa?") e sobre o texto em si ("E nesse texto que a gente leu, na reportagem, a pessoa que escreveu essa reportagem, ela, vocês acham que ela acha que é certo ou errado a pessoa usar cerol?").

Em síntese, vemos que a professora assumiu seu papel de mediadora. $\mathrm{E}$ as crianças, embora ainda não soubessem ler convencionalmente, já haviam incorporado algo fundamental para seu processo de alfabetização: aprender a ler implica produzir sentidos!

\section{Considerações finais}

A análise da mediação das professoras na leitura de reportagens revela o desafio de ensinar crianças pequenas a compreender textos escritos. Ao observar os procedimentos adotados por duas docentes durante a leitura de reportagens para seu grupo de crianças, nos damos conta do quanto esse trabalho é, ao mesmo tempo, complexo e fundamental para a formação do leitor.

Os dados trazidos aqui também apontam que, além das histórias, as crianças podem gostar de ouvir a leitura de reportagens, um gênero, certamente, bem menos familiar para elas. Durante o desenvolvimento da sequência didática não foi, porém, muito simples encontrar exemplares com temas que julgássemos capazes de interessar as crianças e num tamanho razoável para manter sua atenção durante a leitura.

Assim, ao longo da sequência avaliamos que algumas reportagens foram muito bem aceitas e provocaram bastante discussão. Outras, porém, não obtiveram o mesmo sucesso com as crianças, o que, por sua vez, ilustra 
o comportamento de leitores/ouvintes ativos que têm suas preferências e reagem de maneiras distintas diante dos textos.

De fato, um aspecto marcante na análise foi a atitude ativa das crianças em direção à compreensão dos textos que ouviam. Como já enfatizamos, esse foi um dado muito positivo e revelador de um trabalho pedagógico que concebe a leitura como uma atividade de produção de sentidos e não, simplesmente, de extração de informações presentes no texto. Tal resultado também evidencia que as crianças pensam sobre a língua escrita muito precocemente, tal como defendido por Ferreiro e Teberosky (1979).

Finalmente, ressaltamos a necessidade de discutir em cursos de formação inicial e continuada de professsores sobre como se faz para ensinar a compreender textos escritos. É preciso ter clareza que esse ensino não pode esperar para o momento em que as crianças leiam com autonomia ou, simplesmente, acreditar que a compreensão é uma decorrência natural da aprendizagem da leitura.

A história desse ensino começa na educação infantil e não deve ser interrompida nas salas de alfabetização, em nome do trabalho de apropriação do sistema de escrita alfabética. Afinal, como nos alertam Chartier et al. (1996), o ensino de compreensão da escrita deve começar mesmo quando o obstáculo do código ainda não foi transposto, prosseguir durante sua aprendizagem, que está longe de se completar em um ano, e continuar para além desse momento quando as crianças já leem de forma autônoma!

\section{Referências}

BRANDÃO, A.C.P. O ensino da compreensão e a formação do leitor: explorando as estratégias de leitura. In: SOUZA, I.P.; BARBOSA, M.L.F. (Org.). Práticas de leitura no ensino fundamental. Belo Horizonte: Autêntica, 2006. p. 59-75.

BRANDÃO, A.C.P.; ROSA, E.C. A leitura de textos literários na sala de aula: é conversando que a gente se entende. In: PAIVA, A.; MACIEL, F; COSSON, R. (Org.). Explorando a literatura no ensino fundamental. Brasília, DF: MEC, 2010. p. 69-88. Disponível em: <http://portal.mec.gov.br/ index.php?option=com_content $\&$ view=article $\&$ id $=16903 \&$ Itemid $=113>$

CARVALHO, E.F.C. As orientaçôes curriculares e suas relaçôes com as práticas de leitura e produção de textos em sala de aula. 2012. 171f. Dissertação 
(mestrado em Educação) - Centro de Educação, Universidade Federal de Pernambuco, Recife.

CHARMEUX, E. Aprendendo a ler: vencendo o fracasso. São Paulo: Cortez, 1994.

CHARTIER, A.; CLESSE, C.; HERBRARD, J. Ler e escrever: entrando no mundo da escrita. Porto Alegre: Artmed, 1996.

COLOMER, T.; CAMPS, A. Ensinar a ler, ensinar a compreender. Porto Alegre: Artmed, 2002.

FERREIRA, S.P.A.; DIAS, M.G.B.B. Leitor e leituras: considerações sobre gêneros textuais e construção de sentidos. Psicologia: reflexão e crítica, Porto Alegre, v. 18, n. 3, p. 1-14, set./dez. 2005.

FERREIRO, E.; TEBEROSKY, A. Psicogênese da lingua escrita. Porto Alegre: Artmed, 1979.

GIROTTO, C.G.G.S.; SOUZA, R.J. Estratégias de leitura: para ensinar alunos a compreender o que leem. In: MENIN, A.M.C.S. et al. (Org.). Ler e compreender: estratégias de leitura. Campinas: Mercado das Letras, 2010. p. 45-114.

KOCH, I.V.; ELIAS, V.M. Ler e compreender os sentidos do texto. São Paulo: Contexto, 2010.

LEAL, T.F; BRANDÃO, A.C.P. Alfabetização e ensino de lingua portuguesa: investigando o currículo no Brasil. Brasília, DF: CNPq, 2012. (Relatório de pesquisa).

LERNER, D. Ler e escrever na escola: o real, o possível e o necessário. Porto Alegre: Artmed, 2002.

MARCUSCHI, L.A. Produção textual, análise de gêneros e compreensão. São Paulo: Parábola, 2008.

MENIN, A.M.C.S. et al. (Org.). Ler e compreender: estratégias de leitura. Campinas: Mercado das Letras, 2010.

OLIVEIRA, J.B.A.; CASTRO, J.C.J. Aprender a ler: $1^{\circ}$ ano. Brasília, DF: Instituto Alfa e Beta, 2008. 
Conversando sobre textos na alfabetização: o papel da mediação docente

RITER, C. A formação do leitor literário em casa e na escola. São Paulo: Biruta, 2009.

SCHNEUWLY, B.; DOLZ, J. Gêneros orais e escritos na escola. Campinas: Mercado das Letras, 2004.

SOLÉ, I. Estratégias de leitura. Porto Alegre: Artmed, 1998.

Recebido em 30 de setembro de 2012.

Aprovado em 11 de abril de 2013. 